\title{
Preenchimento Perceptivo da Mancha Cega Não Distorce a Percepção do Tamanho Linear
}

\author{
Filling-In of the Blind Spot Does Not Distort Linear Size Perception
}

\author{
Ana Irene Fonseca Mendes* \& Sérgio Sheiji Fukusima \\ Universidade de São Paulo, Ribeirão Preto, Brasil
}

\begin{abstract}
Resumo
Ao se olhar o mundo monocularmente, não se percebe que há uma mancha cega no campo visual correspondente ao disco óptico, região da retina em que não há fotorreceptores. Ao contrário, bordas e padrões de superfícies são percebidos como se fossem detectados por fotorreceptores, fenômeno denominado preenchimento perceptivo. Para investigar se o preenchimento perceptivo distorce o espaço percebido, trinta adultos tiveram suas manchas cegas do olho direito mapeadas e fizeram as comparações de tamanho de pares de barras horizontais em condição monocular direita. Os resultados apontam uma assimetria lateral no campo visual central do olho direito nas comparações de tamanho e que o preenchimento perceptivo na mancha cega não distorce o espaço visual percebido.

Palavras-chave: Preenchimento perceptivo; Mancha cega; Percepção de tamanho linear; Psicofísica; PEST.

Abstract

When looking at the world monocularly, we do not perceive that there is a blind spot in the visual field corresponding to the optic disc, the region of the retina where there are no photoreceptors. In contrast, we perceive edges and patterns of surfaces as if were detected by photoreceptors. This phenomenon is called filling-in. To investigate whether the filling-in distorts space perception, thirty adults had their right eye blind spots mapped and they compared the length of two horizontal bars under right monocular viewing condition. The results point out a lateral asymmetry in the central visual field of the right eye in length comparisons and that the filling-in effect at the blind spot does not distort visual space perception.

Keywords: Filling-in; Blind spot; Linear size perception; Psychophysics; PEST.
\end{abstract}

Devido à inexistência de fotorreceptores, os discos ópticos localizados nas retinas nasais determinam as manchas cegas. Estas regiões estão localizadas a $13-15^{\circ}$ de excentricidade nos hemicampos visuais temporais e cujas extensões máximas variam em torno de $4,5^{\circ}$ de largura por $6^{\circ}$ de altura (Henson, 1993). Estímulos visuais apresentados nessas regiões do campo visual não são percebidos. Porém, mesmo em condições de visão monocular, as manchas cegas não se revelam facilmente à consciência, pois são preenchidas com os padrões de superfície que as circundam. Este fenômeno é conhecido por preenchimento perceptivo (filling-in).
O termo preenchimento perceptivo não é restrito à mancha cega e engloba vários fenômenos visuais em que figuras com algumas de suas partes ausentes (e.g., por sobreposição ou oclusão) são percebidas como completas, evidenciando a capacidade do sistema visual de construir superfícies e transpor lacunas. Exemplos de fenômenos abrangidos por este termo são as bordas ilusórias do triângulo da Kanizsa, a expansão de características de superfícies adjacentes às regiões interpoladas de brilho e cores como do efeito Néon e de texturas como na mancha cega e em escotomas, e até mesmo indução de movimento percebido e profundidade estereoscópica

\footnotetext{
"Endereço para correspondência: Universidade de São Paulo, Faculdade de Filosofia, Ciências e Letras, Departamento de Psicologia e Educação, Av. Bandeirantes, 3900, Bairro Monte Alegre, Ribeirão Preto, SP, Brasil, CEP 14040-901. Tel.: +55 (16) 36023729 ; Fax: +55 (16) 3633 5015. E-mails: anairene@terra.com.br e fukusima@ffclrp.usp.br

Agradecimento especial ao Prof. Dr. Luciano do Fontoura Costa, ao Prof. Dr. José Aparecido da Silva, ao Prof. Dr. Harley Edison Amaral Bicas e ao Ms. Leonardo Gomes Bernardino pela leitura cuidadosa e contribuições no desenvolvimento da pesquisa.
}

Este artigo é parte da dissertação de mestrado "A influência da mancha cega na percepção de tamanho linear "defendida em 2001 pelo programa de Psicobiologia da Faculdade de Filosofia, Ciências e Letras de Ribeirão Preto/Universidade de São Paulo (FFCLRP/USP) Esta pesquisa foi desenvolvida com apoio financeiro da Fundação de Amparo à Pesquisa do Estado de São Paulo (FAPESP) com concessão de bolsa de mestrado a Ana Irene Fonseca Mendes (processo: 98/12653-7) e do Conselho Nacional de Desenvolvimento Científico e Tecnológico $(\mathrm{CNPq})$ com auxílio a Sérgio Sheiji Fukusima (processos: 523275/96-0 e 303592/2005-2). 
(Ramachandran, 1992b; Walls, 1954). O preenchimento perceptivo da mancha cega revela um exemplo claro e natural de preenchimento sendo uma importante oportunidade experimental de testar as regras que regem este fenômeno (Ramachandran \& Blakeslee, 1998).

Uma das controvérsias sobre o preenchimento perceptivo é se há distorção do espaço visual percebido ao interpolar a mancha cega. Três hipóteses sobre os mecanismos neurológicos que geram este fenômeno foram propostas por Tripathy, Levi, Ogmen e Harden (1995). A primeira hipótese, designada explicação associativa, propõe que o córtex preencheria a região correspondente à mancha cega sem distorção do espaço visual percebido. A segunda hipótese, designada explicação retinotópica, propõe que o córtex não preencheria a região correspondente à mancha cega, mas sim, uniria as bordas desta região. Deste modo, o espaço percebido deveria ser distorcido e o erro correspondente a esta distorção seria próximo à extensão da mancha cega onde a imagem do estímulo incidisse. E a terceira hipótese, designada explicação compensatória, propõe que o córtex preencheria a região correspondente a do disco óptico, porém, parcial ou heterogeneamente. Consequentemente, haveria distorção parcial do espaço visual percebido, sendo o erro correspondente a esta distorção menor que a extensão da mancha cega por onde a imagem do estímulo incidisse.

Os resultados das investigações de Tripathy et al. (1995), cujos experimentos consistiram em apresentação dicóptica de duas barras verticais, uma sobre a mancha cega do olho direito e outra de comparação sobre a região do campo visual correspondente à retina temporal do olho esquerdo, indicaram que os erros para comparar os tamanhos das barras eram desprezíveis, favorecendo assim a hipótese associativa. Deve-se enfatizar que este favorecimento ocorreu em uma condição de apresentação dicóptica das barras verticais, isto é, um caso em que as estimulações visuais são processadas em um mesmo hemisfério cerebral.

Outros estudos também sugerem que os estímulos projetados sobre a mancha cega são preenchidos conforme a hipótese associativa. Por exemplo, a proposta do processo cognitivo global do preenchimento perceptivo da mancha cega (Brown \& Thurmond, 1993; Kawabata, 1982, 1984), o preenchimento perceptivo de escotoma de enxaqueca (Lashley, 1941), de escotoma patológico (Bender \& Teuber, 1946; Gerrits \& Timmerman, 1969; Sergent, 1988; Walls, 1954; Zur \& Ullman, 2003) e de escotomas artificiais (Ramachandran, 1992a, 1992b, 1993; Ramachandran \& Gregory, 1991; Ramachandran, Gregory, \& Aiken, 1993) e a ausência de distorção perceptível na grade de Amsler apresentada na mancha cega (Schuchard, 1993). Spillmann, Otte, Hamburger e Magnussen (2006) relataram ocorrer preenchimento perceptivo da mancha cega sem distorção para cor e textura.

Por outro lado, existem estudos cujos resultados indicam a existência de distorção considerável de tamanho provocada pelo preenchimento perceptivo se a imagem recai na mancha cega, favorecendo ou a hipótese retinotópica ou a compensatória. Andrews e Campbell (1991) relataram que uma linha horizontal que passa por toda a extensão da mancha cega, aparenta ser menor que uma similar que não passa. Também não se encontrou redução no comprimento da linha quando uma de suas extremidades desaparece dentro da mancha cega e reaparece após cruzá-la, neste caso, a linha se mostrou alongada a partir do ponto em que havia terminado.

Sears e Mikaelian (1989), utilizando-se do método dos ajustamentos, relataram erros na comparação de comprimentos percebidos de linhas que atravessavam a mancha cega com os comprimentos de linhas que incidiam fora da mancha cega. Eles também encontraram erros na bissecção de linhas que atravessavam a mancha cega, esses resultados são consistentes com a hipótese retinotópica.

Fukusima e Mendes (1998) realizaram um experimento que indica a possibilidade da explicação associativa e compensatória coexistirem nas comparações de tamanhos de barras horizontais. Nesse experimento, mediu-se a extensão horizontal da mancha cega do olho direito no nível do ponto de fixação pelo método dos estímulos constantes. Logo em seguida, duas barras horizontais foram apresentadas pelo método staircase duplo em condição monocular, sendo uma no hemicampo direito, considerada como a barra padrão e outra no hemicampo esquerdo, tida como a barra de comparação. Essa última barra podia ou não cruzar a mancha cega no local mensurado. Eles encontraram uma correlação positiva entre os erros da tarefa de igualar perceptivelmente ambas as barras e a extensão da mancha cega por onde a barra incidia. Os resultados indicaram que se a extensão da mancha cega fosse menor que $5^{\circ}$ a explicação associativa era favorecida, sendo que os erros eram desprezíveis ou a barra de comparação tendia ser ajustada menor que a barra padrão. Porém, na situação experimental em que a extensão da mancha cega era maior que $5^{\circ}$, havia uma tendência em favorecer a explicação compensatória, uma vez que a barra de comparação tendia a ser ajustada maior que a barra padrão e o erro do ajustamento era em torno de $2^{\circ}$ menor que a extensão da mancha cega.

Para explicar os resultados obtidos, Fukusima e Mendes (1998) lançaram a hipótese de que ao redor do disco óptico existiriam células associadas ao preenchimento perceptivo, cuja eficiência em preencher a extensão da mancha cega seria limitada. Sendo assim, se uma barra incidisse sobre a mancha cega interceptando-a somente na região em que o preenchimento é eficiente, favorecerse-ia a explicação associativa. Porém, se a barra incidisse sobre a mancha cega interceptando-a nas áreas em que o preenchimento perceptivo fosse tanto eficiente quanto ineficiente (região central da mancha cega), esperar-seia favorecer a explicação compensatória.

Embora esta hipótese de coexistência tivesse sido sugerida por Fukusima e Mendes (1998), suas condições experimentais não permitiam verificá-la. O método de 
mapeamento da mancha cega não permitiu saber em que região da mancha cega as barras incidiam, se na região central ou periférica.

O experimento de Fukusima e Mendes (1998) foi feito em condição monocular direita, portanto o estímulo projetado sobre a retina temporal do olho direito foi processado no hemisfério direito e o projetado sobre a retina nasal do olho direito foi processado no hemisfério esquerdo. Como há diferenças funcionais entre os hemisférios cerebrais, os autores levantaram outra hipótese quanto à influência dessa assimetria funcional na comparação de tamanho de barras incidindo sobre a mancha cega.

Considerando-se as hipóteses propostas por Tripathy et al. (1995) e os dados controversos sobre distorções na percepção linear de tamanho envolvendo o preenchimento perceptivo na mancha cega, principalmente aqueles obtidos por Fukusima e Mendes (1998), delineou-se este trabalho cujo interesse principal foi investigar se o preenchimento perceptivo que ocorre na mancha cega distorce a percepção de tamanho. Alem disto, duas outras hipóteses foram testadas: a primeira foi que haveria um tempo mínimo para que o fenômeno de preenchimento perceptivo ocorresse, o que foi averiguado manipulando-se o tempo de exposição dos estímulos, e a segunda foi que a distorção do tamanho percebido dependeria da região da mancha cega interceptada pelo estímulo, sendo que quanto maior a extensão da mancha cega, maior a distorção percebida.

\section{Método}

\section{Participantes}

Trinta adultos $(13 \mathrm{H}$ e $17 \mathrm{M})$ com idade entre 17 e 26 anos (média de 19,84 e desvio-padrão de 1,93), acuidade visual normal (medido com um aparelho Orthorater da Bausch \& Lomb, sendo que todos os participantes atingiram o optotipo 10 , equivalente a 20/20 na Tabela de Snellen) em ambos os olhos, sendo 6 com ou 24 sem lentes corretivas, participaram voluntariamente das sessões experimentais após lerem e assinarem o termo de consentimento livre e esclarecido.

\section{Material e Equipamento}

Um microcomputador Pentium 100Hz, $32 \mathrm{MB}$ de RAM, placa de vídeo SIS 6326 PCI de 8MB VRAM, acoplado a um monitor de tela plana de 21" Philips modelo Brilliance 21A foi utilizado para gerar, apresentar os estímulos e coletar os dados. Um apoiador de queixo situado a $40 \mathrm{~cm}$ do monitor foi utilizado para posicionar a cabeça e auxiliar a manter o olhar do observador na direção do centro da tela.

Utilizaram-se três programas computacionais em Turbo Pascal 6.0 executado em DOS na resolução gráfica de 1024 x 768 pixels em 16 cores. A função do primeiro deles foi determinar a localização grosseira das bordas da mancha cega. Este programa gerou e apresentou uma cruz no centro do monitor (ponto de fixação) e círculos com $0,33^{\circ}$ de diâmetro e luminâncias de $65 \mathrm{~cd} / \mathrm{m}^{2}$ no hemicampo direito do monitor.

O segundo programa foi utilizado para estimar a extensão da mancha cega pelo método dos estímulos constantes. O programa gerou e apresentou um ponto de fixação no centro do monitor em forma de cruz. A cada tentativa, o ponto de fixação se transformava em quadrado e dois círculos equidistantes do centro do monitor eram apresentados simultaneamente. Os círculos possuiam diâmetros de $0,33^{\circ}$ de ângulo visual e luminâncias de 65 $\mathrm{cd} / \mathrm{m}^{2}$. O número de tentativas e de pares de círculos apresentados, o tempo de exposição dos círculos e as suas excentricidades na tela foram fornecidos no início da execução do programa. O programa armazenou as coordenadas dos círculos no monitor, o tempo de reação (em milisegundos) e a resposta do observador.

O terceiro programa foi utilizado para gerar e apresentar os estímulos pelo método PEST (Parameter Estimation by Sequential Testing) (Macmillan \& Creelman, 1991). Havia um ponto de fixação em forma de cruz no centro da tela do monitor. Os estímulos foram duas barras horizontais brancas de luminância de $65 \mathrm{~cd} / \mathrm{m}^{2}$ apresentadas na metade vertical da tela do monitor. As extremidades internas das barras eram equidistantes do ponto de fixação. No momento e durante o mesmo intervalo de tempo em que as barras foram apresentadas, o ponto de fixação se transformava em quadrado. Os tamanhos e tempo de exposição das barras foram fornecidos no início da execução do programa. O programa armazenou o tamanho dos estímulos apresentados, o tempo de reação e a resposta do observador.

\section{Procedimento}

Cada participante realizou três sessões experimentais de aproximadamente 50 minutos cada. Nas duas primeiras sessões foram mapeadas suas manchas cegas e na terceira eles compararam comprimentos de barras horizontais. Os intervalos entre as sessões podiam variar entre 2 e 48 horas, dependendo da disponibilidade dos participantes. Todas as sessões foram executadas numa câmara escura, os participantes tiveram o olho esquerdo ocluído e a cabeça posicionada no apoiador de queixo, de maneira que o olho direito mirasse diretamente ao centro da tela do monitor.

Mapeamento da Mancha Cega. Primeiramente foi feita uma localização "grosseira" das bordas esquerda, direita, superior e inferior da mancha cega. No centro da tela do monitor, em fundo negro, foi apresentado um ponto de fixação (cruz branca) e um círculo (branco com $0,33^{\circ}$ de diâmetro) na metade direita da tela em quatro posições diferentes: meio das bordas superior, inferior, direita e esquerda. Os círculos brancos foram deslocados pelo experimentador, pressionando teclas específicas do teclado, no sentido das bordas para o centro do hemicampo direito da tela. A tarefa do observador era manter o olhar fixo no centro da tela e indicar ao experimentador quando o círculo deslocado havia desaparecido de seu campo 
visual. $\mathrm{O}$ procedimento se repetiu três vezes para cada posição do círculo branco. A distância entre as médias aritméticas das coordenadas das bordas esquerda e direita determinou a largura e a das coordenadas das bordas superior e inferior determinou a altura da mancha cega "grosseira".

Essas altura e largura "grosseiras" foram utilizadas para fornecer o tamanho mínimo e excentricidade de uma matriz de círculos que abrangesse toda extensão da mancha cega e, a partir daí, ser feito seu mapeamento pormenorizado. A quantidade de círculos da matriz foi determinada de maneira que fosse mantido um intervalo de $1,0^{\circ}$ de ângulo visual entre os círculos adjacentes.

O mapeamento pormenorizado da mancha cega consistiu em apresentar em fundo negro um ponto de fixação (cruz branca) no centro da tela do monitor por $500 \mathrm{~ms}$. Logo em seguida, um quadrado era apresentado no local do ponto de fixação e, simultaneamente, um par de círculos brancos, um à direita e outro à esquerda equidistantes do ponto de fixação por $100 \mathrm{~ms}$. Em cada tentativa, a tarefa do observador era, mantendo o olhar fixo no ponto de fixação, indicar se havia percebido dois círculos ou um círculo pressionando teclas específicas do teclado.
Cada par de círculos foi apresentado seis vezes pelo método dos estímulos constantes. O mapeamento da mancha cega foi estabelecido ao conectar as coordenadas na matriz de círculos do hemicampo visual direito, onde o círculo fora percebido em $50 \%$ das tentativas. E essas coordenadas foram determinadas por interpolação linear.

Para checar a precisão do método de mapeamento, foi feita uma segunda sessão seguindo o mesmo procedimento. A média entre os parâmetros das duas sessões foi adotada como tamanho final da mancha cega.

Comparação de Tamanhos das Barras Horizontais. Após localizar a região e o tamanho da mancha cega no campo visual direito, os participantes foram submetidos à sessão de comparação de tamanhos de barras horizontais. No centro da tela foram apresentados, por $500 \mathrm{~ms}$, uma cruz branca como ponto de fixação e, logo em seguida, duas barras horizontais, uma à direita e a outra à esquerda e no mesmo nível do ponto de fixação (Fig. 1). As extremidades das barras voltadas para o centro da tela eram equidistantes $\left(0,57^{\circ}\right)$ do ponto de fixação. A tarefa do observador foi indicar qual barra era a maior pressionando teclas predeterminadas no teclado.

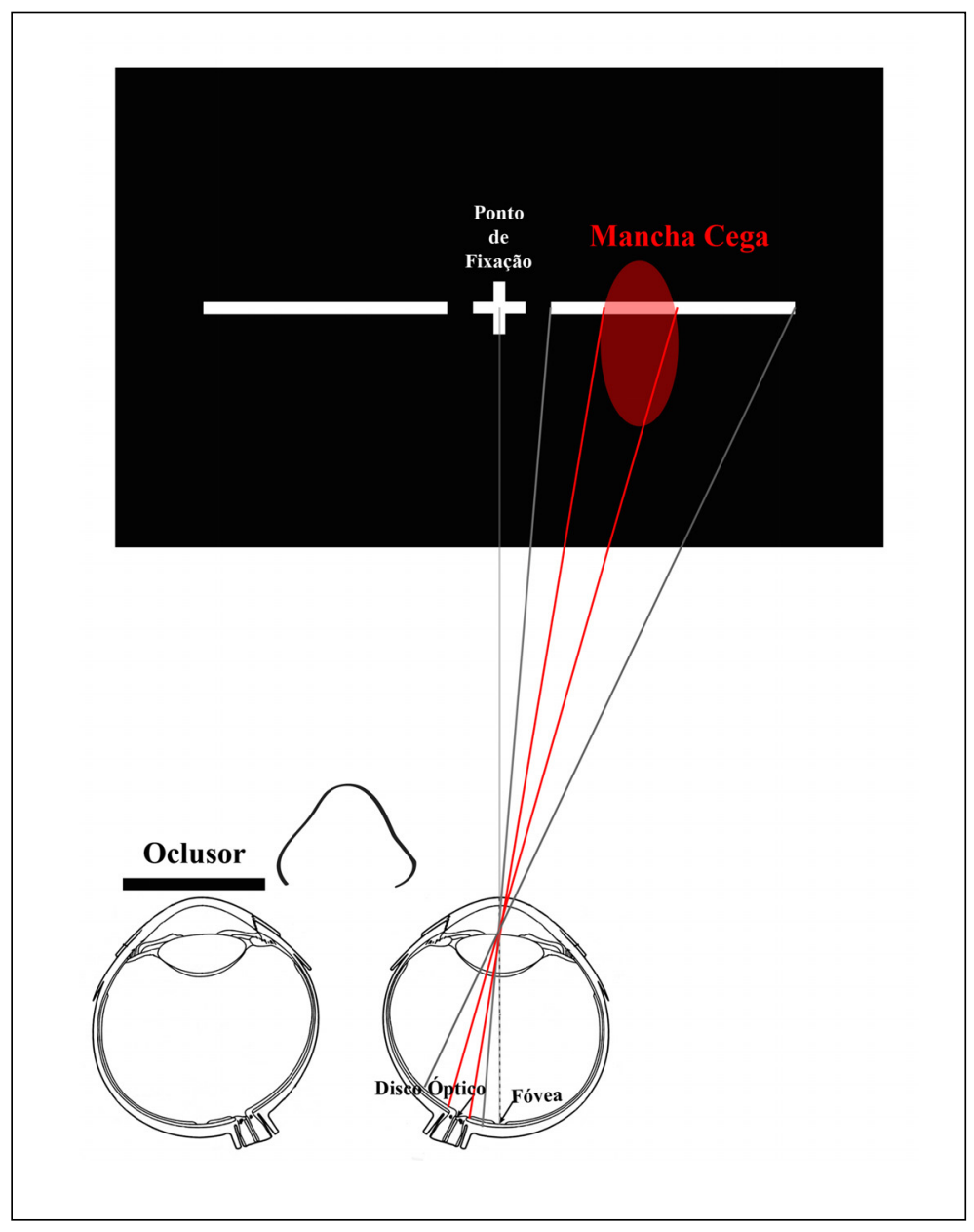

Figura 1. Esquema da situação experimental para a apresentação dos estímulos das comparações de barras horizontais 
As larguras das barras eram de $0,17^{\circ}$. Os comprimentos da barra padrão foram determinados de modo que um deles fosse curto o suficiente $\left(8,52^{\circ}\right)$ para não atingir a mancha cega, outro suficientemente longo $\left(16,13^{\circ}\right)$ para interceptá-la parcialmente e, finalmente, um longo o bastante $\left(21,72^{\circ}\right)$ para interceptá-la por completo. O tempo de exposição das barras podia ser de 100,300 ou 400ms. As barras foram apresentadas pelo método PEST com duas sequências de tentativas, uma em que a barra padrão foi apresentada à esquerda do ponto de fixação e outra em que foi apresentada à direita.

Para que fosse possível a análise estatística do efeito principal do tempo de exposição da barra e do tamanho padrão da barra, bem como das possíveis interações entre estes fatores e o hemicampo de apresentação da barra, foram elaborados dois delineamentos experimentais, cada um com 3 grupos independentes de 5 participantes. No Delineamento Experimental I (Grupos I, II e III) estabeleceu-se o tempo de exposição das barras como fator fixo entre os grupos e o tamanho da barra e o hemicampo visual onde foi apresentada a barra padrão como fatores de medidas correlacionadas (ou repetidas). No Delineamento Experimental II (Grupos IV, V e VI) estabeleceu-se o tamanho da barra como fator fixo entre os grupos e o tempo de exposição e o hemicampo visual como fatores de medidas correlacionadas.

\section{Resultados}

\section{Extensões da Mancha Cega}

A extensão horizontal da mancha cega no nível do ponto de fixação, sua altura máxima e a localização do nível horizontal no ponto fixação, em relação à extremidade superior da mancha cega, foram estimadas para cada participante a partir dos mapeamentos individuais da mancha cega do olho direito na primeira e segunda sessão. Foi encontrado que a mancha cega no campo visual tem forma irregular, variando em forma, tamanho e excentricidade.

As medidas das extensões horizontais da primeira e segunda sessão foram correlacionadas utilizando-se o teste de correlação de Pearson, cujo coeficiente de correlação foi 0,78 ; $\operatorname{com} p<0,01$. Como as mensurações individuais da segunda sessão apresentaram variações em relação às da primeira, tomou-se a média das mensurações das duas sessões como a estimativa individual da extensão da mancha cega. As extensões horizontais da mancha cega, quando analisadas individualmente, variaram de $0^{\circ}$ (situação em que a mancha cega encontrava-se com a extremidade superior abaixo ou tangível a extensão horizontal) a $5,97^{\circ}$. A média das extensões horizontais da mancha cega entre os participantes foi de $3,87^{\circ}$, com desvio padrão de $1,31^{\circ}$.

Para determinar em que região da mancha cega se localizava o ponto de fixação, calculou-se a altura máxima da mancha cega no mapeamento, mediu-se a distância entre o nível da extensão horizontal e a extremidade superior da mancha cega e tomou-se a razão entre esta distância e a altura máxima. O coeficiente de correlação de Pearson entre as alturas máximas da mancha cega da primeira e da segunda sessão foi de 0,71 , com $p<0,01$. O coeficiente de correlação de Pearson entre as distâncias da extensão horizontal e a extremidade superior foi de 0,84 , com $p<0,01$. As razões médias entre essas extensões variavam entre $0,01^{\circ}$ e $0,53^{\circ}$. Isto significava que a extensão horizontal da mancha cega, relativa ao ponto de fixação, podia estar situada fora da mancha cega ou quase que tangível a sua extremidade superior ou, ainda, interceptá-la quase ao meio de sua altura máxima. Entretanto, a razão média entre as distâncias foi de $0,25^{\circ}$, com desvio-padrão de $0,14^{\circ}$, indicando que há uma tendência de que a extensão horizontal intercepte a mancha cega a um quarto de sua altura máxima a partir da extremidade superior. O coeficiente de correlação de Pearson de 0,77 , $\operatorname{com} p<0,01$; entre a razão e a extensão horizontal indicou que esta extensão horizontal aumenta à medida que ela intercepta a mancha cega próxima ao meio de sua altura.

\section{Comparação de Tamanhos das Barras Horizontais}

As médias dos pontos de igualdade subjetiva (PIS), dos erros constantes (EC) e seus respectivos erros padrão para os grupos dos Delineamentos Experimentais I (fator independente: tempo de exposição das barras) e II (fator independente: tamanho da barra) foram calculadas. Cabe ressaltar que um EC positivo indica que a barra de comparação foi ajustada maior que a barra padrão, enquanto que um valor negativo aponta que a teste foi ajustada menor que a padrão.

Optou-se por analisar os ECs, e não os PIS, visto que podiam informar diretamente sobre os erros nas comparações de tamanhos da barras sob a influência dos fatores envolvidos. Assim, as médias dos ECs e seus respectivos erros padrão da média foram traçados em função do tamanho da barra padrão para ambos os delineamentos experimentais, as quais são apresentadas nas Figuras 2 e 3.

As médias dos ECs do Delineamento Experimental I foram submetidas a uma ANOVA de três fatores [3 tempos de exposição x ( 2 posições da barra nos hemicampos visuais $\mathrm{x} 3$ tamanhos da barra)] com medidas repetidas nos dois últimos fatores. A análise indicou efeito significativo do tamanho da barra, $F(2,24)=3,99 ; p<0,05$, e da interação entre tamanho e posição da barra nos hemicampos, $F(2,24)=4,96 ; p<0,05$. Não houve efeito significativo do tempo de exposição, $F(2,12)<1,0$; da posição da barra, $F(1,12)<1,0$; das interações duplas entre posição e tempo de exposição, $F(2,12)<1,0$ e entre tamanho e tempo de exposição, $F(4,24)=1,49 ; p>0,5$ e da interação tripla entre tempo de exposição, posição e tamanho da barra, $F(4,24)<1,0$. 


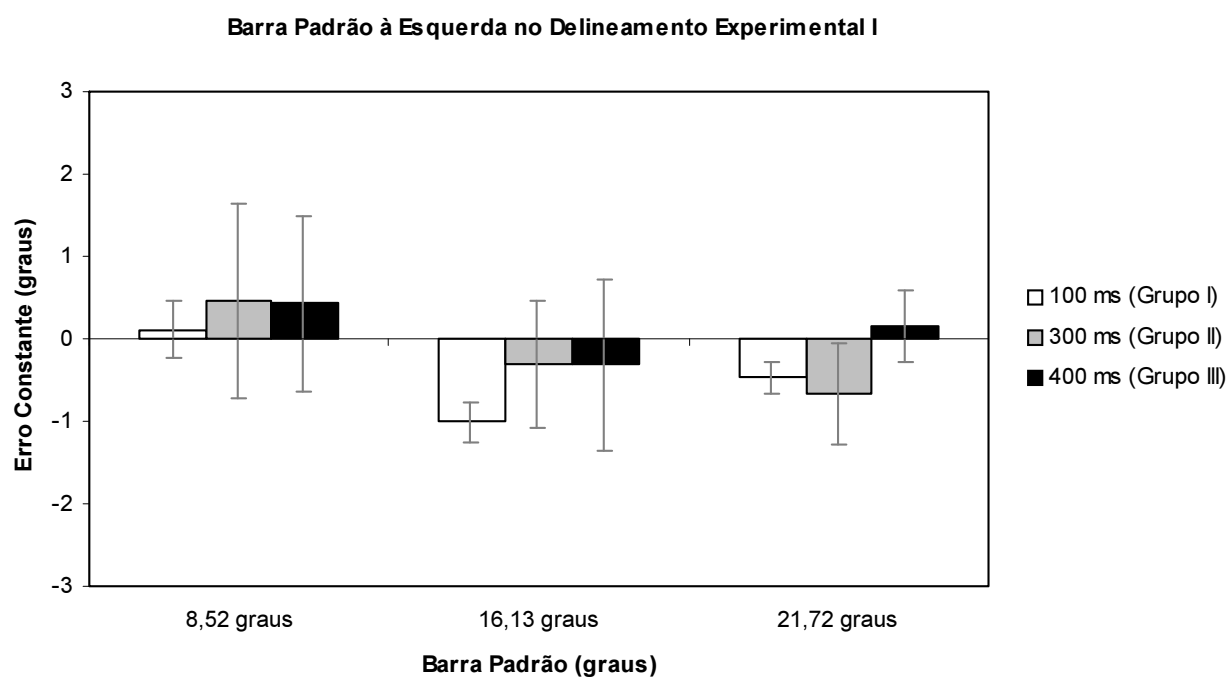

(A)

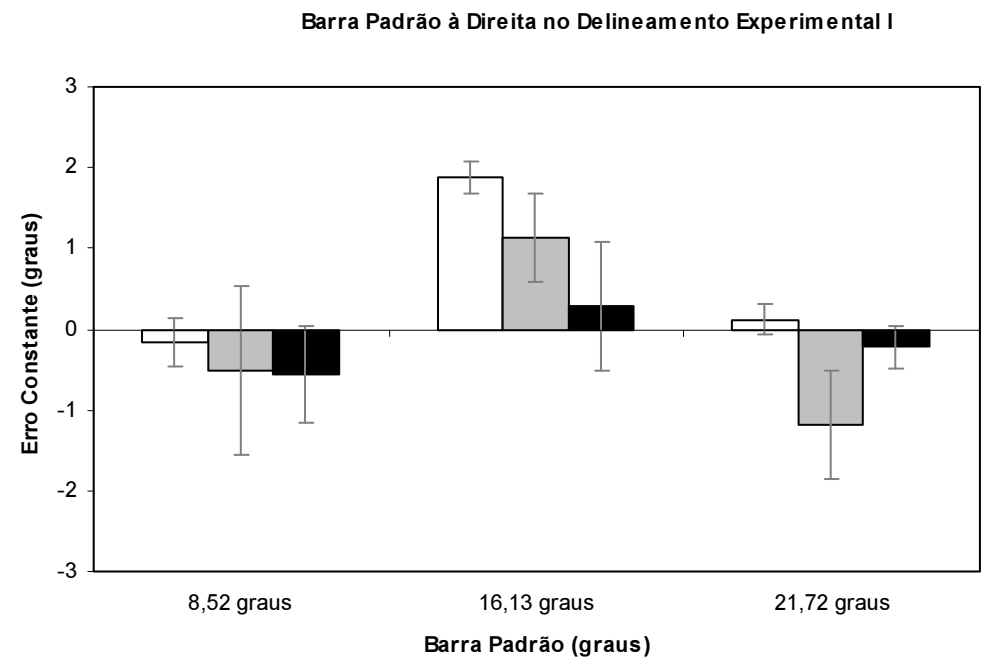

口 $100 \mathrm{~ms}$ (Grupo I)

口300 ms (Grupo II

- 400 ms (Grupo III)

(B)

Figura 2. Médias dos erros constantes dos três tamanhos da barra padrão, nos três tempos de exposição dos estímulos, com os respectivos erros padrão do Delineamento Experimental I

Nota. (A) Condição em que a barra padrão foi apresentada à esquerda do ponto de fixação. (B) Condição em que a barra padrão foi apresentada à direita do ponto de fixação.

Devido à interação significativa entre tamanho e posição da barra nos hemicampos, a análise dos ECs foi desmembrada em outras ANOVAs, em que se consideraram os níveis destes fatores isoladamente. Destas análises, houve efeito significativo do tamanho da barra se esta estiver no hemicampo visual direito, ou seja, à direita do ponto de fixação, $F(2,24)=9,50 ; p<0,01$. Nota-se na Figura 2, que nesta situação somente os erros do tamanho de $16,13^{\circ}$ diferenciam-se dos erros dos demais tama- nhos. E que somente há efeito significativo da posição da barra nos hemicampos para aquela de tamanho menor, $F(1,12)=6,88 ; p<0,01$.

Haja vista não ter sido encontrado efeito significativo do fator tempo de exposição e nem interação deste com outros fatores, os ECs foram reagrupados em função do tamanho da barra e de sua posição no hemicampo visual e submetidos ao teste $t$ de Student. O resultado deste teste indicou que a média dos ECs para a barra menor é signi- 


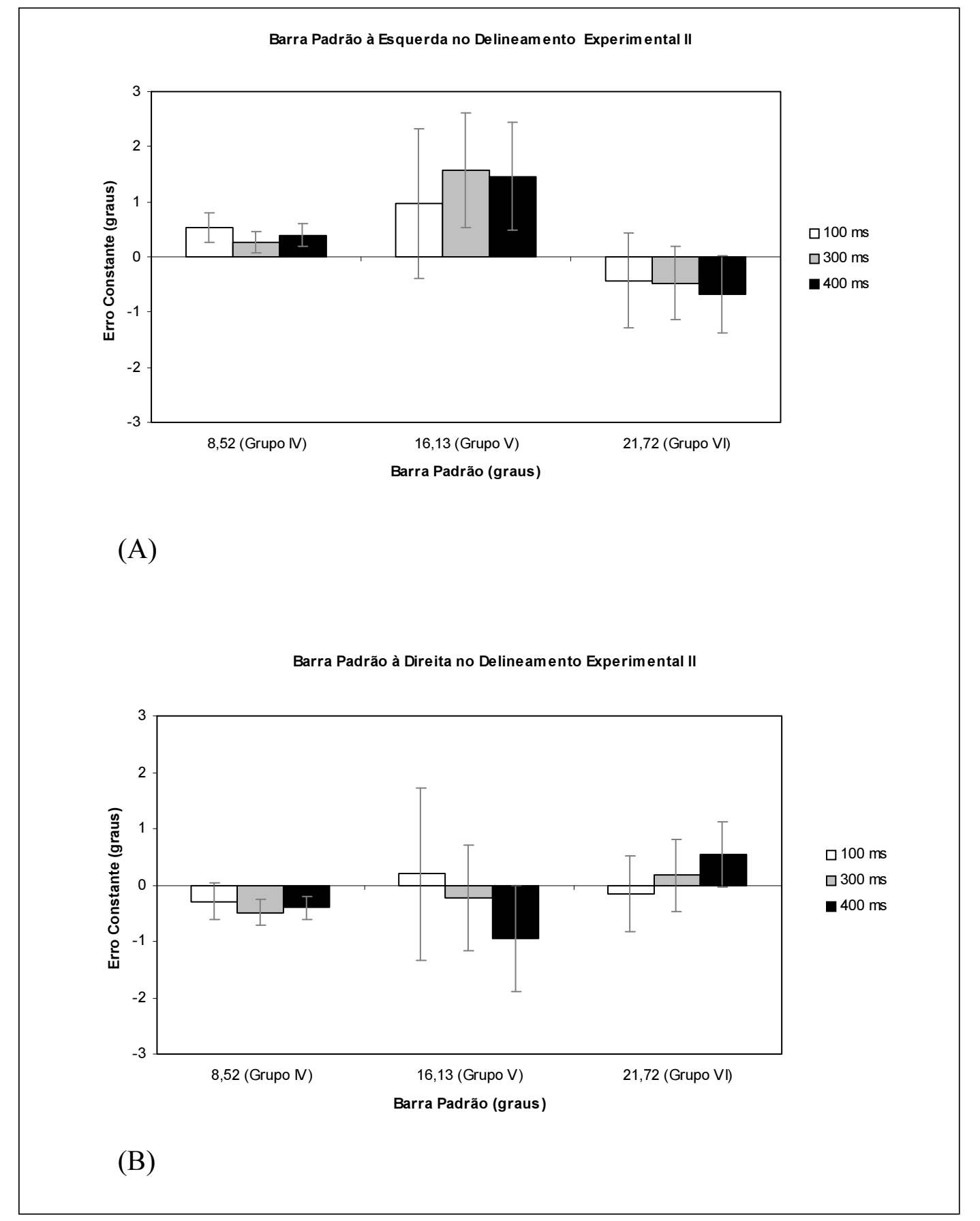

Figura 3. Médias dos erros constantes dos três tamanhos da barra padrão, nos três tempos de exposição dos estímulos, com os respectivos erros padrão do Delineamento Experimental II

Nota. (A) Condição em que a barra padrão foi apresentada à esquerda do ponto de fixação. (B) Condição em que a barra padrão foi apresentada à direita do ponto de fixação

ficativamente diferente de zero, tanto na condição em que se encontrava no hemicampo visual esquerdo, $t(14)=2,28$; $p<0,05$, quanto no hemicampo direito, $t(14)=-3,11$; $p<0,01$. Para a barra intermediária, somente a média de ECs na condição em que ela se encontrava no hemicampo visual direito se diferiu significativamente de zero, $t(14)=2,42 ; p<0,05$. As demais médias de ECs não foram significativamente diferentes de zero, $p>0,05$.
Similarmente, os ECs do Delineamento Experimental II foram também submetidos a uma ANOVA de três fatores $[3$ tamanhos de barra $\mathrm{x}$ ( 2 posições da barra nos hemicampos visuais x 3 tempos de exposição)], porém com medidas repetidas nos fatores posição da barra nos hemicampos visuais e tempo de exposição. A análise indicou somente efeito significativo do tamanho da barra, $F(2,12)=15,51 ; p<0,001$. A saber, os efeitos que não 
foram significativos: posição da barra, $F(1,12)<1,0$; tempo de exposição, $F(2,24)<1,0$; interação entre posição e tamanho da barra, $F(2,12)<1,0$; interação entre tempo de exposição e tamanho da barra, $F(4,24)=1,69 ; p>0,05$; interação entre posição da barra e tempo de exposição, $F(2,24)<1,0$ e interação tripla entre posição, tamanho e tempo de exposição das barras, $F(4,24)<1,0$.

Os ECs neste delineamento experimental foram também reagrupados, desconsiderando o fator tempo de exposição, em função do tamanho da barra padrão e sua posição no hemicampo visual e submetidos ao teste $t$ de Student. O teste indicou que a média dos ECs para a barra menor diferiu significativamente de zero, tanto na condição em que se encontrava no hemicampo esquerdo, $t(14)=3,33 ; p<0,01)$, quanto na condição em que se encontrava no hemicampo direito, $t(14)=-2,87 ; p<0,05$. Para a barra de tamanho intermediário, a média dos erros foi significativamente diferente de zero somente na condição em que ela se encontrava no hemicampo visual esquerdo, $t(14)=2,17 ; p<0,05$. As médias dos ECs dos demais grupamentos não diferiram significativamente de zero $(p>0,05)$.

Em ambos os delineamentos experimentais, independente se a barra padrão estava à esquerda ou à direita do ponto de fixação, as médias dos erros para a barra maior, que interceptou totalmente a mancha cega, foram bem menores que a extensão da mancha cega e estatisticamente não diferiram de zero, evidenciando que o preenchimento perceptivo ocorre sem distorcer o tamanho percebido.

A barra de tamanho intermediário, que interceptou parcialmente a mancha cega, apresentou resultados ambíguos. Além de apresentar geralmente grande variabilidade, as médias dos erros diferiram significativamente de zero, como na condição em que a barra padrão foi apresentada à direita do ponto de fixação no Delineamento Experimental I e na condição em que a barra padrão foi apresentada à esquerda no Delineamento Experimental II, indicando preenchimento perceptivo com distorção do tamanho percebido. Entretanto, as médias nas demais condições em que esta barra foi apresentada, não diferiram significativamente de zero, sugerindo a inexistência de distorção de tamanho percebido.

A barra de tamanho menor, que nunca interceptou a mancha cega, apresentou as médias dos ECs significativamente diferentes de zero em todas as condições, indicando que existe a tendência da barra horizontal no hemicampo visual direito ser maior que uma barra horizontal no hemicampo esquerdo ao serem julgadas de igual tamanho. Isto parece evidenciar uma assimetria lateral na percepção de tamanho na região central do campo visual do olho direito.

\section{Relação entre o Erro Constante e a Extensão da Mancha Cega}

Com a finalidade de pormenorizar a análise, os ECs individuais foram traçados em função das respectivas extensões da mancha cega interceptadas no nível do pon- to de fixação, do tamanho da barra padrão e do tempo de exposição das barras. Os coeficientes de correlação de Pearson entre os erros constantes e a extensão da mancha cega para cada tamanho de barra padrão em cada tempo de exposição foram calculados e em nenhum dos casos foram significativamente diferentes de zero $(p>0,01)$.

Os coeficientes de correlação de Pearson foram calculados desconsiderando-se o tempo de exposição e, mais uma vez, não foram significativamente diferentes de zero $(p>0,01)$. Enfatiza-se, portanto, que não houve uma relação sistemática entre os erros constantes e as extensões da mancha cega, independentemente se as barras não interceptavam a mancha cega, se a interceptavam parcialmente ou se a interceptavam por completo.

\section{Discussão}

Os resultados deste experimento evidenciam que o tempo de exposição do estímulo não afeta os erros de julgamento ao se comparar tamanhos percebidos e, portanto, parece não influenciar no processo de preenchimento perceptivo. Além disso, não ocorreu, para nenhum dos tempos de exposição relatados, a percepção descontínua das barras maiores que atingiam a mancha cega. Ou seja, o preenchimento perceptivo de barras horizontais sobre a mancha cega deve ser um processo que ocorre mais rápido do que se imaginava e ela, certamente, ocorre para estímulos expostos por $100 \mathrm{~ms}$.

A inexistência de erros significativamente diferentes de zero para as barras de $21,72^{\circ}$, que interceptavam totalmente a mancha cega, e a inexistência de uma correlação sistemática entre os erros constantes e a extensão da mancha cega favorecem a hipótese de que o preenchimento perceptivo ocorre sem distorção espacial e sem depender da extensão da mancha cega. Sob a perspectiva de Tripathy et al. (1995), estes resultados seriam consistentes com a explicação associativa e não apoiariam em primeira instância a hipótese proposta por Fukusima e Mendes (1998), de que a explicação associativa e a explicação compensatória podem coexistir, devido ao preenchimento perceptivo ser mais eficiente na região periférica da mancha cega e menos eficiente na região central.

Havendo similaridades entre este experimento e aquele de Fukusima e Mendes (1998), então o que poderia ter conduzido a resultados interpretados como divergentes? Uma possível resposta a esta questão seria o efeito da atenção ao se comparar os tamanhos percebidos. No experimento de Fukusima e Mendes (1998), as barras foram comparadas de maneira que a barra padrão era apresentada sempre à esquerda do ponto de fixação e a barra teste sempre à direita pelo método staircase duplo. Além disso, enfatizava-se ao participante que em cada tentativa ele deveria julgar se a barra de comparação à direita era maior ou menor que a barra padrão à esquerda. Por não haver alteração da localização das barras entre os hemicampos visuais naquele procedimento, $o$ 
participante poderia focar sua atenção mais frequentemente no hemicampo visual direito, local em que a barra de comparação estava localizada. A possibilidade de que a atenção afetaria a percepção de tamanho é apoiada por alguns trabalhos, que evidenciam que ela pode modificar o tamanho percebido (Masin, 1999; Tsal \& Shalev, 1996) ou a sua variabilidade (Prinzmetal \& Wilson, 1997). Assim, os resultados de Fukusima e Mendes (1998) poderiam ser interpretados como favoráveis à hipótese de coexistência da explicação associativa e compensatória do preenchimento perceptivo.

Entretanto, no presente experimento, o controle da atenção foi mais eficiente, de maneira que ela foi focada no ponto de fixação no centro da tela do computador e distribuída equitativamente em ambos hemicampos visuais, evitando assim seu efeito na comparação de tamanho. Isto foi possível devido à alternação aleatória na localização da barra padrão entre os hemicampos visuais e à adaptação do método de escolha forçada nas tentativas de apresentação das barras pelo método PEST. A escolha forçada consistiu em indicar em que hemicampo visual, direito ou esquerdo, a barra maior estava localizada.

O método de escolha forçada é amplamente utilizado na teoria de detecção de sinal para gerar medidas livres de fatores alheios à percepção, como a motivação e mesmo a atenção. Assim, a inexistência do efeito da atenção na comparação de tamanho, possivelmente conduziu a estes resultados que favorecem somente a explicação associativa no preenchimento perceptivo.

Outra possibilidade da interpretação divergente entre os resultados desses experimentos refere-se à extensão da mancha cega por onde a barra incidia e, se este local, seria uma região periférica ou central da mancha cega. No experimento de Fukusima e Mendes (1998) não houve o mapeamento extensivo da mancha cega e, portanto, não foi possível determinar se os estímulos incidiam numa região periférica ou central. Sabe-se, entretanto, que naquele experimento a extensão da mancha no nível do ponto de fixação variou de $4^{\circ}$ a $7^{\circ}$ aproximadamente e, que neste experimento, esta variação se estendeu de $0^{\circ}$ a $6^{\circ}$ aproximadamente. $\mathrm{O}$ primeiro valor extremo corresponde à situação em que toda a mancha cega se encontrava abaixo do nível do ponto de fixação e o outro valor extremo corresponde a situação em que o nível do ponto de fixação incidia quase no meio da altura da mancha cega. $\mathrm{Na}$ média, o nível do ponto de fixação interceptava a mancha cega a $25 \%$ de sua altura a partir de sua extremidade superior neste experimento, o que caracteriza uma região praticamente periférica.

Assim, poder-se-ia supor que o preenchimento perceptivo sem distorções de tamanho ocorreu porque as barras incidiam na região periférica da mancha cega e, portanto, esperar-se-iam dados favoráveis à explicação associativa neste experimento. A inexistência de dados favoráveis à explicação compensatória deve-se, possivelmente, à insuficiência de casos em que a barra incidia na região mais central da mancha cega na amostra de participantes. Este fato provavelmente não ocorreu no experimento de Fukusima e Mendes (1998), pois as extensões da mancha cega naquele experimento foram maiores que as extensões neste experimento. Se considerado esta possibilidade, a divergência entre os dois experimentos seria somente aparente, pois ela surge devido a uma peculiaridade da amostra de participantes.

A verificação dessa explicação seria possível se a incidência da barra na mancha cega fosse controlada de maneira que ela fosse apresentada propositadamente na sua região periférica e central. Infelizmente, a execução de um piloto deste experimento mostrou que não era possível apresentar barras horizontais em níveis diferentes daquele do nível do ponto de fixação, variando-se a localidade de incidência na mancha cega, sem ocasionar movimento ocular abrupto durante a comparação de tamanhos.

Os dados da barra intermediária também permitem interpretações interessantes. Esta barra interceptou a mancha cega parcialmente, isto é, ela interceptou a mancha cega somente em um local de sua borda. Ela apresentou erros geralmente com grande variabilidade e os erros médios eram desprezíveis em certas condições, sugerindo-se que havia preenchimento perceptivo sem distorção de tamanho. Em outras condições, os erros médios eram significativamente diferentes de zero, sugerindo-se que havia preenchimento perceptivo com distorção de tamanho, similar aos dados relatados por Araragi e Nakamizo (2008) e Spillmann et al. (2006). Uma possível explicação para essa variação é a hipótese da interpolação neural da mancha cega proposta por Fiorani, Rosa, Gattass e Rocha-Miranda (1992). Uma vez que as barras interceptaram a mancha cega somente em um ponto da borda, elas estimulariam com menos eficiência as células nervosas responsáveis pelo preenchimento perceptivo do que as barras que a interceptam em dois pontos opostos de sua borda, como ocorre para a barra maior deste experimento.

E por fim, os dados da barra menor, que não atingiu a mancha cega, evidenciam uma assimetria lateral no campo visual central do olho direito na comparação de tamanho no meridiano horizontal e central. Esta assimetria é evidenciada também na partição de linhas (Milner, Brechmann, \& Pagliarini, 1992) e parece ser mais forte na região central do que na periferia do campo visual, como indicada por Fukusima e Faubert (2001). A questão é se esta assimetria também acontece nas excentricidades que atingem ou ultrapassam a mancha cega, pois poderia ser outro fator envolvido no preenchimento perceptivo da mancha cega.

A questão que fica em aberto é qual a vantagem do cérebro executar o preenchimento perceptivo e, segundo os resultados apresentados, pelo menos para barras horizontais, o faz com bastante acurácia. Umas das explicações possíveis é baseada na teoria evolutiva do sistema 
visual, levando em consideração a tendência à economia no processamento visual. É bem provável que a representação mental dos objetos seja parecida com um esboço e, para preencher o que estaria faltando no objeto, o sistema visual utilizaria regularidades estatísticas (e.g., contornos são contínuos e que texturas são uniformes) e faria a interpolação de contornos e superfícies economizando cálculos e o ônus de uma inspeção detalhada.

\section{Referências}

Andrews, P. R., \& Campbell, F. W. (1991). Images at the blind spot. Nature, 353, 308.

Araragi, Y., \& Nakamizo, S. (2008). Anisotropy of tolerance of perceptual completion at the blind spot. Vision Research, 48, 618-625.

Bender, M. B., \& Teuber, H. L. (1946). Phenomena of fluctuation, extinction, and completion in visual perception. Archives of Neurology and Psychiatry, 55, 627-658.

Brown, R. J., \& Thurmond, J. B. (1993). Preattentive and cognitive effects on perceptual completion at the blind spot. Perception \& Psychophysics, 53, 200-209.

Fiorani, M., Jr., Rosa, M. G. P., Gattass, R., \& Rocha-Miranda, C. E. (1992). Dynamic surrounds of receptive fields in primate striate cortex: A physiological basis for perceptual completion? Proceedings of the National Academy of Science of the U.S.A., 89, 8547-8551.

Fukusima, S. S., \& Faubert, J. (2001). Perceived lenght in the central visual field: Evidence for visual field asymmetries. Vision Research, 41, 2119-2126.

Fukusima, S. S., \& Mendes, A. I. F. (1998). Does the blind spot distort the perceived length of a line? Investigative Ophthalmology \& Visual Science, 39(4), S621.

Gerrits, H. J. M., \& Timmerman, G. J. M. E. N. (1969). The filling in process in patients with retinal scotomata. Vision Research, 9, 439-442.

Henson, D. B. (1993). Visual fields. New York: Oxford University Press.

Kawabata, N. (1982). Visual information processing at the blind spot. Perceptual \& Motor Skills, 55, 95-104.

Kawabata, N. (1984). Perception at the blind spot and similarity grouping. Perception \& Psychophysics, 36, 151-158.

Lashley, K. S. (1941). Patterns of cerebral integration indicated by the scotomas of migraine. Archives of Neurology and Psychiatry, 46, 331-339.

Macmillan, N. A., \& Creeman, C. D. (1991). Detection theory: A user's guide. New York: Cambridge University Press.

Masin, S. (1999). Attention and estimated line length. Perceptual and Motor Skills, 88, 831-842.

Milner, A. D., Brechmann, M., \& Pagliarini, L. (1992). To halve and to halve not: An analysis of line bisection judgments in normal subjects. Neuropsychologia, 30, 515-526.

Prinzmetal, W., \& Wilson, A. (1997). The effect of attention on phenomenal lenght. Perception, 26, 193-205.

Ramachandran, V. S. (1992a). Filling in gaps in perception: Part I. Current Directions in Psychological Science, 1, 199205.

Ramachandran, V. S. (1992b). Blind Spots. Scientific American, 266, 86-91.

Ramachandran, V. S. (1993). Filling in gaps in perception: Part II. Scotomas and phantom limbs. Current Directions in Psychological Science, 2, 56-65.
Ramachandran, V. S., \& Blakeslee, S. (1998). Phantoms in the brain: Probing the mysteries of the human mind. New York: William Morrow.

Ramachandran, V. S., \& Gregory, R. L. (1991). Perceptual filling-in of artificially induced scotomas in human vision. Nature, 350, 699-702.

Ramachandran, V. S., Gregory, R. L., \& Aiken, W. (1993). Perceptual fading of visual texture borders. Vision Research, 33, 717-721.

Sears, C. R., \& Mikaelian, H. H. (1989). Explorations of perceptual functioning surround the optic disk. Canadian Psychology, 30, 408.

Sergent, J. (1988). An investigation into perceptual completion in blind areas of visual field. Brain, 111, 347-373.

Schuchard, R. A. (1993). Validity and interpretation of Amsler grid reports. Archives of Ophthalmology, 111, 776-780.

Spillmann, L., Otte, T., Hamburger, K., \& Magnussen, S. (2006). Perceptual filling-in from the edge of the blind spot. Vision Research, 46, 4252-4257.

Tripathy, S. P., Levi, D. M., Ogmen, H., \& Harden, C. (1995). Perceived length across the physiological blind spot. Visual neuroscience, 12, 385-402.

Tsal, Y., \& Shalev, L. (1996). Inattention magnifies perceived lenght: The attentional receptive fields hypothesis. Journal of Experimental Psychology: Human Perception and Performance, 22, 233-243.

Walls, G. L. (1954). The filling-in process. American Journal of Optometry \& Archives of American Academy of Optometry, 31, 329-341.

Zur, D., \& Ullman, S. (2003). Filling-in of retinal scotomas. Vision Research, 43, 971-982. 